\title{
A comparison of palonosetron and dexamethasone for postoperative nausea and vomiting in orthopedic patients receiving patient-controlled epidural analgesia
}

\author{
Byung-Gun Kim, Hyunzu Kim, Hyun-Kyoung Lim, Chunwoo Yang, \\ Sora Oh, and Byung-Wook Lee \\ Department of Anesthesiology and Pain Medicine, Inha University Hospital, Inha University School of Medicine, \\ Incheon, Korea
}

\begin{abstract}
Background: Postoperative nausea and vomiting (PONV) is one of the major concerns after anesthesia and surgery, and it may be more frequent in orthopedic patients receiving patient-controlled epidural analgesia (PCEA). The purpose of this study was to compare the effect of palonosetron and dexamethasone on the prevention of PONV in patients undergoing total joint arthroplasty and receiving PCEA.

Methods: Patients scheduled for total hip or knee arthroplasty under spinal anesthesia/PCEA were randomly allocated to receive either intravenous palonosetron $(0.075 \mathrm{mg}, \mathrm{n}=50)$ or dexamethasone $(5 \mathrm{mg}, \mathrm{n}=50)$. Treatments were administered intravenously to the patients $30 \mathrm{~min}$ before the beginning of surgery. The total incidence of PONV and incidence in each time period, severity of nausea, need for rescue anti-emetics, pain score, and adverse effects during the first $48 \mathrm{~h}$ postoperatively were evaluated.

Results: The total incidence of PONV was lower in the palonosetron group compared with the dexamethasone group (18.4\% vs. $36.7 \%, \mathrm{P}=0.042)$, but there were no statistically significant differences in incidence between the groups at all time points. No significant intergroup differences were observed in the severity of nausea, use of rescue anti-emetics, pain score, and adverse effects.

Conclusions: Although there were no significant differences in the incidence of PONV between the treatment groups at all time points, intravenous palonosetron reduced the total incidence of PONV in orthopedic patients receiving PCEA compared with dexamethasone.
\end{abstract}

Key Words: Dexamethasone, Epidural analgesia, Palonosetron, Patient-controlled analgesia, Postoperative nausea and vomiting.

Corresponding author: Chunwoo Yang, M.D.

Department of Anesthesiology and Pain Medicine, Inha University Hospital, Inha University School of Medicine, 27, Inhang-ro, Jung-gu, Incheon 22332, Korea

Tel: 82-32-890-3968, Fax: 82-32-881-2476, Email: everycw@daum.net.

ORCID: https://orcid.org/0000-0002-9147-3879

Received: December 21, 2016. Revised: February 21, 2017 (1st); February 27, 2017 (2nd). Accepted: March 19, 2017.

Korean J Anesthesiol 2017 October 70(5): 520-526

https://doi.org/10.4097/kjae.2017.70.5.520

(c) This is an open-access article distributed under the terms of the Creative Commons Attribution Non-Commercial License (http://creativecommons.org/ licenses/by-nc/4.0/), which permits unrestricted non-commercial use, distribution, and reproduction in any medium, provided the original work is properly cited. 


\section{Introduction}

Postoperative pain control is essential for fast functional recovery through early rehabilitation, early return to daily life, and the welfare of patients after orthopedic limb surgery. Compared with intravenous patient-controlled analgesia (PCA), patientcontrolled epidural analgesia (PCEA) enables effective pain control, fast intestinal motility recovery, and shortened hospital stay [1]. However, PCEA may result in several side effects due to the combined use of both local anesthetic and opioids [24]. Among the side effects, postoperative nausea and vomiting (PONV) occurs frequently and has a major negative impact on patient satisfaction. PONV can be caused by either the surgery or the anesthesia itself, but it can also be caused by the opioid contained in the PCEA $[2,3,5]$.

Dexamethasone is known to reduce the incidences of PONV in children and adults [6]. Tarantino et al. [7] reported that the use of dexamethasone is effective in reducing nausea and vomiting by $28 \%$ after thyroidectomy. It was also effective in preventing nausea and vomiting associated with epidural opioid in patients undergoing open gynecologic surgery [4]. However, the use of dexamethasone may result in a reduction in glycemic control capability, increased wound infection or delayed wound healing, gastritis, and avascular necrosis [8].

Serotonin 5-hydroxytryptamine type $3\left(5-\mathrm{HT}_{3}\right)$ receptor antagonists have been commonly used to prevent chemotherapyinduced nausea and vomiting, as well as PONV $[9,10]$. Compared with older $5-\mathrm{HT}_{3}$ receptor antagonists, palonosetron has been widely used in recent years because of its advantages such as no $\mathrm{QT}_{\mathrm{c}}$ prolongation and longer half-life. However, there is little information about the use of palonosetron as prophylaxis against nausea and vomiting induced by PCEA containing opioids.

Therefore, the purpose of this study was to compare the effects of palonosetron and dexamethasone on PONV in patients undergoing total joint arthroplasty and receiving PCEA. The primary outcome was the overall incidence of PONV during the first $48 \mathrm{~h}$ postoperatively. Secondary outcomes were the incidence of PONV at 2, 24, and $48 \mathrm{~h}$, the severity of nausea, use of rescue anti-emetics, pain scores, and side effects.

\section{Materials and Methods}

Institutional Review Board approval and written informed consent were obtained for this randomized, double-blind study. A total of 100 patients aged 20 to 80 years with an American Society of Anesthesiologists physical status of 1 to 3 who were scheduled to undergo total hip or knee arthroplasty and who wished to receive PCEA for postoperative pain control were recruited. Exclusion criteria were contraindication to regional anesthesia (coagulation disorders and infection at the injection site), pregnancy, administration of anti-emetics or steroids within $24 \mathrm{~h}$ before surgery, liver or kidney disease, neuropsychiatric disorders, and hypersensitivity to local anesthetic.

Using a computer-generated sequence of random numbers and sealed envelopes, patients were assigned to either the palonosetron group (group P) or dexamethasone group (group D). All envelopes were opened after induction of anesthesia by an attending nurse who was not involved in the study. The patients, anesthesiologists who performed the blocks, surgeons, and research assistants collecting outcome data were blinded to group allocation.

After arriving at the operating room, the patients were monitored continuously for blood pressure, heart rate, electrocardiogram, and peripheral oxygen saturation. Before induction, the patients received glycopyrrolate $0.2 \mathrm{mg}$ and midazolam $2 \mathrm{mg}$ intravenously.

In both groups, patients received combined spinal-epidural anesthesia with subarachnoid administration of $8 \mathrm{mg}$ of $0.5 \%$ hyperbaric bupivacaine at the L3-4 or L4-5 intervertebral space with the patient in the lateral decubitus position. Then, using an $18 \mathrm{G}$ Tuohy needle, the epidural space was confirmed by the method of loss of resistance using 1.5-2 ml air at the same level. A catheter was passed cephalad $3 \mathrm{~cm}$ past the needle tip and fixed after checking that no blood or cerebrospinal fluid was aspirated. Sensory blockade was targeted for over T12 and it was tested by a pin-prick test every 5 minutes for up to 15 minutes after the injection. If the sensory block was insufficient, $5 \mathrm{ml}$ of $0.75 \%$ ropivacaine was injected through the epidural catheter as supplementation.

Patients were treated with prophylactic antibiotics $30 \mathrm{~min}$ before the beginning of the surgery. The study drugs (palonosetron $0.075 \mathrm{mg}$ for group $\mathrm{P}$ and dexamethasone $5 \mathrm{mg}$ for group $\mathrm{D}$, respectively) were administered to the patients in each group prior to the injection of prophylactic antibiotics. The study drug for injection was prepared as $1 \mathrm{ml}$ of clear solution in identical syringes.

Supplemental oxygen was administered throughout the procedure at $6 \mathrm{~L} / \mathrm{min}$ through a mask. All the patients received an intravenous infusion of dexmedetomidine (loading dose of 0.1 $\mu \mathrm{g} / \mathrm{kg} / \mathrm{min}$ over $10 \mathrm{~min}$ followed by $0.008 \mu \mathrm{g} / \mathrm{kg} / \mathrm{min}$ ) for sedation throughout the procedure. Doses were adjusted to maintain a bispectral index value between 60 and 70 . If the value fell more than $20 \%$ compared with the baseline blood pressure, ephedrine $10 \mathrm{mg}$ was given. Every $60 \mathrm{~min}$ after the start of surgery, $5 \mathrm{ml}$ of $0.75 \%$ ropivacaine was injected through the epidural catheter. On arrival at the postanesthesia care unit, an infusion of $0.2 \%$ ropivacaine $(100 \mathrm{ml}$ in total) and $1 \mu \mathrm{g} / \mathrm{ml}$ sufentanil $(100 \mathrm{ml}$ in total) was started and continued for $48 \mathrm{~h}(2 \mathrm{ml} / \mathrm{h}$ basal; 0.5 $\mathrm{ml}$ bolus; $15 \mathrm{~min}$ lockout) using an elastomeric infusion pump 
(Anaplus ${ }^{\circledR}$, EWHA Meditech, Goyang, Korea).

The incidence of PONV (nausea, retching, and vomiting) and severity of nausea were recorded by direct questioning by research assistants blinded to the study group or recorded by the patients at the time points of 2, 24, and $48 \mathrm{~h}$ in reference to symptom occurrence during the prior observation period. Nausea was defined as the subjectively unpleasant sensation associated with awareness of the urge to vomit regardless of its severity. For the purpose of data collection, vomiting included retching (an involuntary attempt to vomit but without expulsion of gastric content) and vomiting (expulsion of gastric content). If nausea or vomiting was documented at any of these time points, it was considered PONV. The severity of nausea was rated from 0 (no nausea) to 10 (worst possible nausea). Rescue anti-emetics (ondansetron $4 \mathrm{mg}$ ) were given for PONV upon patient's request or complaint of nausea (severity of nausea $\geq 4$ ) or vomiting and the number of injections was noted. Postoperative pain was assessed using a numerical rating scale (NRS, $0=$ no pain; $10=$ worst imaginable pain) at 2, 24, and $48 \mathrm{~h}$ after surgery. Rescue analgesia with $25 \mathrm{mg}$ of intravenous meperidine to a maximum of $75 \mathrm{mg} / 24 \mathrm{~h}$ was available on demand. Other adverse effects, such as headache, dizziness, drowsiness, pruritus, constipation, wound infection or delayed wound healing, paresthesia, and motor weakness were also recorded.

\section{Statistical analysis}

SPSS version 19 (SPSS Inc., Chicago, IL, USA) was used for statistical analysis. Normality of the data was tested using the Kolmogorov-Smirnov test. Normally distributed continuous variables were presented as means and SD and analyzed using Student's $t$-test. Non-normally distributed data were presented as median with 25 th and 75 th percentiles and analyzed using the Mann-Whitney $U$ test. Categorical variables were defined as the number of patients (\%) and analyzed using the Chi-square test or Fisher's exact test, as appropriate. A P value $<0.05$ was considered statistically significant. Bonferroni correction for multiple repeated measurements was used for analysis of incidence of PONV at any time point, severity of nausea, and pain scores. In this case, a $\mathrm{P}$ value $<0.017(=0.05 / 3)$ was considered significant.

Sample size calculation was based on a previous study, which observed a $40 \%$ incidence of PONV in the dexamethasone group after surgery [11]. Assuming a 10\% incidence of PONV in the palonosetron group, it was estimated that the sample size should be 40 patients per group using $\alpha=0.05$ and $\beta=0.1$ for a two-sided test of difference. We enrolled 50 patients per group to allow for possible dropouts.

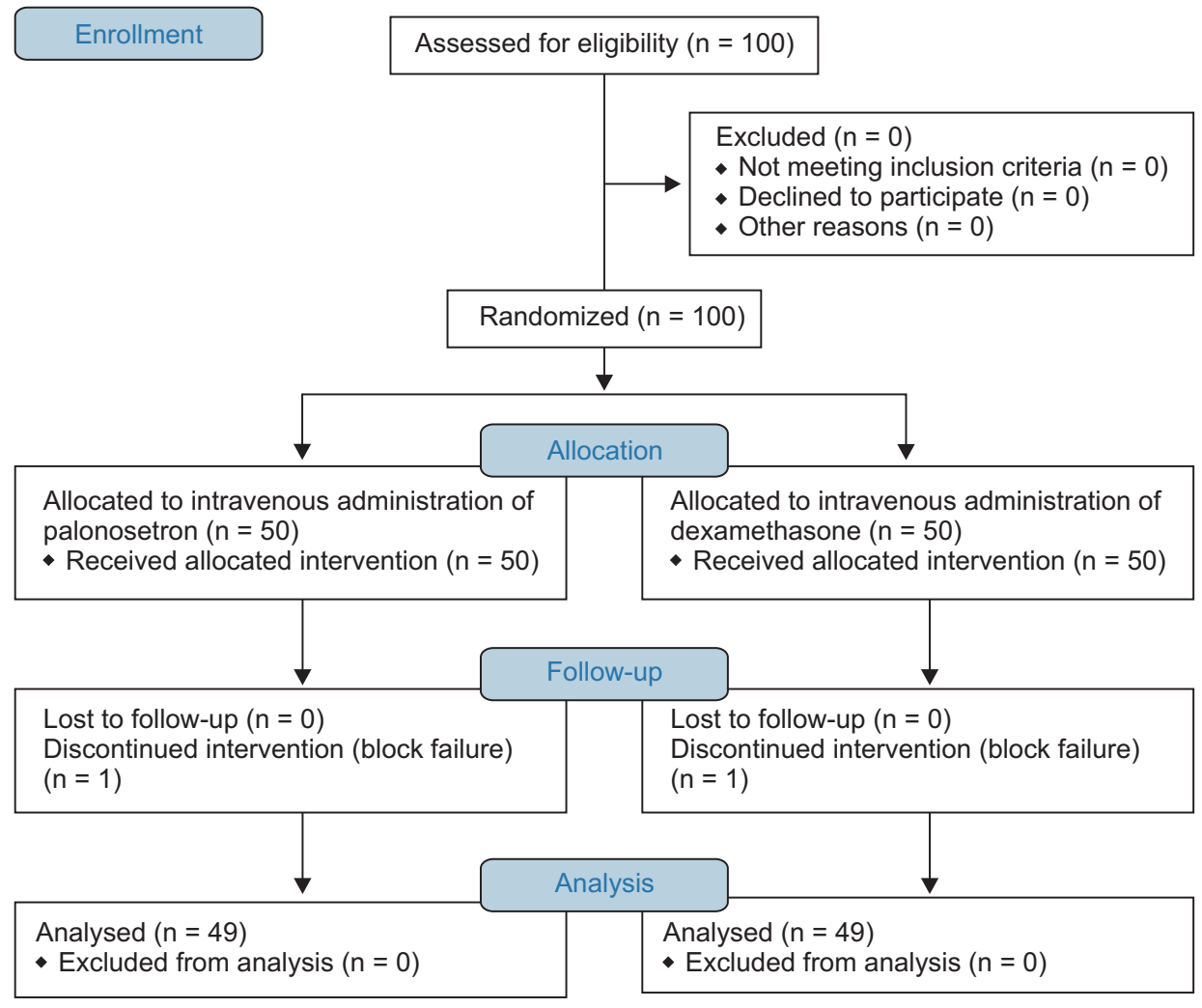

Fig. 1. Trial CONSORT diagram. 


\section{Results}

One hundred patients were enrolled in this study. One patient from each group was excluded because of a technical failure of spinal or epidural block. A total of 98 patients were included in the study (Fig. 1). Patient characteristics, Apfel risk score, type of surgery, and duration of the operation were comparable in both groups (Table 1).

The total incidence of PONV was significantly lower in the group P than group D ( $18.4 \%$ vs. $36.7 \%, \mathrm{P}=0.042$, Table 2$)$. However, there were no statistically significant differences in both groups during the $0-2 \mathrm{~h}, 2-24 \mathrm{~h}$, and $24-48 \mathrm{~h}$ periods (Table 2). The severity of postoperative nausea was not significantly different between the two groups at all time intervals after surgery

Table 1. Demographic and Clinical Data

\begin{tabular}{lcc}
\hline & Group P $(\mathrm{n}=49)$ & Group D $(\mathrm{n}=49)$ \\
\hline Age $(\mathrm{yr})$ & $63 \pm 11$ & $62 \pm 11$ \\
Sex $(\mathrm{F})$ & 36 & 31 \\
Weight $(\mathrm{kg})$ & $61 \pm 11$ & $66 \pm 11$ \\
Height $(\mathrm{cm})$ & $156 \pm 10$ & $160 \pm 9$ \\
Apfel risk score & & \\
1 & 5 & 5 \\
2 & 9 & 14 \\
3 & 31 & 24 \\
4 & 4 & 6 \\
Type of surgery & & 22 \\
THA & 16 & 27 \\
TKA & 33 & $131 \pm 53$ \\
Operation time (min) & $128 \pm 52$ & \\
\hline
\end{tabular}

Values are expressed as mean \pm SD or number of patients. Group P: palonosetron $0.075 \mathrm{mg}$ IV, Group D: dexamethasone $5 \mathrm{mg}$ IV. THA: total hip arthroplasty, TKA: total knee arthroplasty.
(Table 3). The numbers of patients requiring rescue anti-emetics were not significantly different between the groups $(P=0.372$, Table 3).

There was no statistically significant difference in postoperative pain during the study periods (Table 3 ). In addition, supplemental meperidine consumption was similar between both groups ( $\mathrm{P}=0.176$, Table 3 ). One patient in each group complained dizziness. There were no significant differences between the two groups considering potential adverse effects.

\section{Discussion}

This study demonstrated that palonosetron resulted in a lower total incidence of PONV than dexamethasone in patients receiving PCEA after hip or knee replacement surgery. However, there were no differences in the incidence of PONV at any time point, severity of nausea, use of rescue anti-emetics, pain score, and adverse effects.

PONV is one of a major contributing factor that negatively influences patient satisfaction after surgery. Although a contributor to PONV has not been clearly proven till now, various

Table 2. Incidence of PONV

\begin{tabular}{lccc}
\hline & Group P $(\mathrm{n}=49)$ & Group D $(\mathrm{n}=49)$ & P value \\
\hline Total incidence & $9(18.4)$ & $18(36.7)$ & 0.042 \\
$0-2 \mathrm{~h}^{*}$ & $0(0)$ & $2(4.1)$ & 0.093 \\
$2-24 \mathrm{~h}^{*}$ & $8(16.3)$ & $16(32.7)$ & 0.060 \\
$24-48 \mathrm{~h}^{*}$ & $5(10.4)$ & $14(28.6)$ & 0.024 \\
\hline
\end{tabular}

Values are number of patients (\%). Group P: palonosetron $0.075 \mathrm{mg}$ IV, Group D: dexamethasone $5 \mathrm{mg}$ IV. PONV: postoperative nausea and vomiting. *A significant $\mathrm{P}$ value as determined by Bonferroni-adjusted alpha level $(\alpha=0.017)$ in individual comparisons between $0-2 \mathrm{~h}, 2-24 \mathrm{~h}$, and $24-48 \mathrm{~h}$ periods.

Table 3. Severity of Nausea, Use of Rescue Anti-emetic, Pain Score, and Use of Rescue Opioid

\begin{tabular}{|c|c|c|c|}
\hline & Group P $(\mathrm{n}=49)$ & Group D $(\mathrm{n}=49)$ & $P$ value \\
\hline \multicolumn{4}{|l|}{ Severity of nausea (NRS $0-10$ ) } \\
\hline $0-2 \mathrm{~h}^{*}$ & $0(0-0)$ & $0(0-0)$ & 0.153 \\
\hline $2-24 h^{*}$ & $0(0-0)$ & $0(0-2.5)$ & 0.060 \\
\hline $24-48 \mathrm{~h}^{*}$ & $0(0-0)$ & $0(0-1.5)$ & 0.024 \\
\hline Rescue anti-emetics & $5(10.2)$ & $8(16.3)$ & 0.372 \\
\hline \multicolumn{4}{|l|}{ Pain (NRS 0-10) } \\
\hline At $2 \mathrm{~h}^{+}$ & $0(0-0)$ & $0(0-0)$ & 0.118 \\
\hline At $24 \mathrm{~h}^{\dagger}$ & $3.5(3-5)$ & $3(3-5)$ & 0.686 \\
\hline At $48 \mathrm{~h}^{\dagger}$ & $3(3-5)$ & $3(2-3)$ & 0.074 \\
\hline Rescue opioid consumption (mg) & $0(0-25)$ & $0(0-25)$ & 0.176 \\
\hline No. of patients requiring rescue opioid & $24(49.0)$ & $17(35.4)$ & 0.176 \\
\hline
\end{tabular}

Values are median (25th, 75th percentiles) or number of patients (\%). Group P: palonosetron 0.075 mg IV, Group D: dexamethasone 5 mg IV. NRS: numerical rating scale. *A significant $P$ value as determined by Bonferroni-adjusted alpha level $(\alpha=0.017)$ in individual comparisons between $0-2 \mathrm{~h}, 2-24 \mathrm{~h}$, and $24-48 \mathrm{~h}$ periods. ${ }^{\dagger} \mathrm{A}$ significant $\mathrm{P}$ value as determined by Bonferroni-adjusted alpha level $(\alpha=0.017)$ in individual comparisons between $2 \mathrm{~h}, 24 \mathrm{~h}$, and $48 \mathrm{~h}$ time points. 
factors are implicated. The reported risk factors are female sex, history of PONV or motion sickness, non-smokers, young age, general anesthesia, the use of volatile anesthetics and nitrous oxide, opioids, duration of anesthesia, and type of surgery [12]. The mechanism of opioids-induced nausea and vomiting could be explained by several factors, including the increased sensitivity of the vestibular system, direct impact on the chemoreceptor trigger zone, and delayed gastric emptying [13]. Therefore, a necessary drug to prevent such a risk has to be co-administered because PCEA that include opioids may result in an increased risk of PONV.

In this study, the total incidence of PONV was lower in group $\mathrm{P}$ than in group D. However, the incidence of PONV at each time period and severity of nausea were not significantly different between the groups. The exact reason for these results is not clear, but it may be explained by a lack of power due to the small sample size in this study.

Dexamethasone is an inexpensive and effective anti-emetic that has been widely used as the drug of choice to prevent chemotherapy-induced nausea and vomiting, as well as PONV that occurs after general anesthesia [6]. In addition, dexamethasone is known to be effective in the prevention of PONV caused by epidural opioid administration for postoperative pain [14]. Although the antiemetic mechanism of dexamethasone is not yet clearly known, it is proposed to be the depletion of GABA ( $r$-aminobutyric acid) storage, decrease in toxins associated with vomiting permeating through the blood brain barrier, inhibition of encephalin release from the brainstem, and synthesis and suppression of release of central serotonin [14]. Lee et al. [15] reported that the minimum effective dose of dexamethasone for the prevention of PONV associated with intravenous PCA containing morphine was $8 \mathrm{mg}$. Wang et al. [16] evaluated the antiemetic effects of various doses of dexamethasone and recommended $5 \mathrm{mg}$ of dexamethasone as the minimum effective dose for prophylaxis against epidural morphine-related nausea and vomiting in parturients. However, a high dose or long-term use of dexamethasone may cause side effects such as glucose intolerance, wound infection, and delayed wound healing $[4,8]$. Therefore, it is necessary to use the minimum effective dose for preventing nausea and vomiting after surgery, and in this study, $5 \mathrm{mg}$ of dexamethasone was chosen.

The serotonin $5-\mathrm{HT}_{3}$ receptor antagonist has an antiemetic effect through its competitive binding to the $5-\mathrm{HT}_{3}$ receptor. Palonosetron is the newest $5-\mathrm{HT}_{3}$ receptor antagonist, with a greater receptor binding affinity than the older $5-\mathrm{HT}_{3}$ receptor antagonists and a longer half-life of 40 hours. A recent study [17] showed that a single dose of palonosetron $0.075 \mathrm{mg}$ reduced the incidence of PONV during the first $72 \mathrm{~h}$ after surgery. It was more effective in the prevention of PONV than older $5-\mathrm{HT}_{3}$ receptor antagonists [18]. Furthermore, combination treatment using palonosetron and dexamethasone was more effective in the prevention of PONV compared with dexamethasone only in patients receiving IV PCA after general anesthesia [10]. A recent study reported that palonosetron was more effective in the prevention of PONV than ramosetron after cesarean section under spinal anesthesia [19]. A previous study evaluated older $5-\mathrm{HT}_{3}$ antagonists for the prophylaxis of PONV in patients receiving PCEA containing an opioid after total knee arthroplasty [20]. Compared with ondansetron, ramosetron was more effective in preventing PONV associated with PCEA. However, few studies have compared palonosetron with dexamethasone in preventing nausea and vomiting associated with continuous administration of epidural opioid.

In this study, there were no differences in pain scores and consumption of supplemental analgesics between the two groups. A previous study reported that the $5-\mathrm{HT}_{3}$ receptor is involved in the modulation of nociceptive transmission [21]. Lee et al. [22] reported that the pain score in the palonosetron group was lower than that of the control group. In addition, in a previous study on the effects of dexamethasone on pain, administration of dexamethasone resulted in reduced pain score, length of hospital stay, and opioid consumption compared with control after total knee arthroplasty [23]. Conversely, there were no statistically significant differences in the pain scores between dexamethasone and control groups of patients undergoing cesarean section after the administration of epidural morphine [16].

Consistent with previous studies, there were no adverse effects observed in this study, such as dizziness, drowsiness, constipation, headache, and wound infection $[10,14,16]$. The long-term use of corticosteroids was associated with several side effects, such as increased risk of infection, glucose intolerance, delayed wound healing, superficial ulceration of gastric mucosa, and adrenal suppression, but no hazards were shown with a single dose [16]. Allen et al. [14] reported that there were no side effects, such as delayed wound healing, wound infection, and restlessness, when $2.5-10 \mathrm{mg}$ dexamethasone was administered to parturients receiving epidural morphine. Headache and dizziness are the most common side effects of the $5-\mathrm{HT}_{3}$ receptor antagonist. However, a previous study reported that there was not significantly difference in the incidence of side effects between the palonosetron and placebo groups [17].

This study has some limitations. First, although we compared two different anti-emetics, combination anti-emetic therapy is recommended for patients at moderate or high risk of PONV [12]. Second, we used ondansetron as rescue anti-emetics in this study. Since it is also a $5-\mathrm{HT}_{3}$ receptor antagonist, an antiemetic with a different mechanism is more desirable. Third, midazolam and dexmedetomidine were administered to achieve intravenous sedation of patients during sensory block and surgery, respectively. These drugs have an anti-emetic effect [24,25]. 
Fourth, we did not include a placebo control group to evaluate the baseline incidence of PONV. However, it is unethical to withhold anti-emetics in patients at high risk of PONV. Finally, patient satisfaction was not included as an outcome variable in this study. It is an important patient-reported endpoint.

In conclusion, this study demonstrated that intravenous palonosetron reduced the total incidence of PONV in orthopedic patients receiving PCEA compared with dexamethasone.

\section{Acknowledgments}

This study was supported by an Inha University Research grant.

The authors would like to thank all the study participants for their participation in this study.

\section{ORCID}

Hyun Kyoung Lim, https://orcid.org/0000-0003-2694-1258

Chunwoo Yang, https://orcid.org/0000-0002-9147-3879

\section{References}

1. Zhu Z, Wang C, Xu C, Cai Q. Influence of patient-controlled epidural analgesia versus patient-controlled intravenous analgesia on postoperative pain control and recovery after gastrectomy for gastric cancer: a prospective randomized trial. Gastric Cancer 2013; 16: 193200.

2. Chaney MA. Side effects of intrathecal and epidural opioids. Can J Anaesth 1995; 42: 891-903.

3. Gadsden J, Hart S, Santos AC. Post-cesarean delivery analgesia. Anesth Analg 2005; 101(5 Suppl): S62-9.

4. Ho ST, Wang JJ, Tzeng JI, Liu HS, Ger LP, Liaw WJ. Dexamethasone for preventing nausea and vomiting associated with epidural morphine: a dose-ranging study. Anesth Analg 2001; 92: 745-8.

5. Habib AS, Gan TJ. Evidence-based management of postoperative nausea and vomiting: a review. Can J Anaesth 2004; 51: 326-41.

6. Henzi I, Walder B, Tramèr MR. Dexamethasone for the prevention of postoperative nausea and vomiting: a quantitative systematic review. Anesth Analg 2000; 90: 186-94.

7. Tarantino I, Warschkow R, Beutner U, Kolb W, Lüthi A, Lüthi C, et al. Efficacy of a single preoperative dexamethasone dose to prevent nausea and vomiting after thyroidectomy (the tPONV study): a randomized, double-blind, placebo-controlled clinical trial. Ann Surg 2015; 262: 934-40.

8. Ho CM, Wu HL, Ho ST, Wang JJ. Dexamethasone prevents postoperative nausea and vomiting: benefit versus risk. Acta Anaesthesiol Taiwan 2011; 49: 100-4.

9. Gralla R, Lichinitser M, Van Der Vegt S, Sleeboom H, Mezger J, Peschel C, et al. Palonosetron improves prevention of chemotherapyinduced nausea and vomiting following moderately emetogenic chemotherapy: results of a double-blind randomized phase III trial comparing single doses of palonosetron with ondansetron. Ann Oncol 2003; 14: 1570-7.

10. Ryoo SH, Yoo JH, Kim MG, Lee KH, Kim SI. The effect of combination treatment using palonosetron and dexamethasone for the prevention of postoperative nausea and vomiting versus dexamethasone alone in women receiving intravenous patient-controlled analgesia. Korean J Anesthesiol 2015; 68: 267-73.

11. Lee HK, Lee JH, Chon SS, Ahn EK, Kim JH, Jang YH. The effect of transdermal scopolamine plus intravenous dexamethasone for the prevention of postoperative nausea and vomiting in patients with epidural PCA after major orthopedic surgery. Korean J Anesthesiol 2010; 58: 50-5.

12. Gan TJ, Diemunsch P, Habib AS, Kovac A, Kranke P, Meyer TA, et al. Consensus guidelines for the management of postoperative nausea and vomiting. Anesth Analg 2014; 118: 85-113.

13. Smith HS, Laufer A. Opioid induced nausea and vomiting. Eur J Pharmacol 2014; 722: 67-78.

14. Allen TK, Jones CA, Habib AS. Dexamethasone for the prophylaxis of postoperative nausea and vomiting associated with neuraxial morphine administration: a systematic review and meta-analysis. Anesth Analg 2012; 114: 813-22.

15. Lee Y, Lai HY, Lin PC, Lin YS, Huang SJ, Shyr MH. A dose ranging study of dexamethasone for preventing patient-controlled analgesiarelated nausea and vomiting: a comparison of droperidol with saline. Anesth Analg 2004; 98: 1066-71.

16. Wang JJ, Ho ST, Wong CS, Tzeng JI, Liu HS, Ger LP. Dexamethasone prophylaxis of nausea and vomiting after epidural morphine for postCesarean analgesia. Can J Anaesth 2001; 48: 185-90.

17. Chun HR, Jeon IS, Park SY, Lee SJ, Kang SH, Kim SI. Efficacy of palonosetron for the prevention of postoperative nausea and vomiting: a randomized, double-blinded, placebo-controlled trial. Br J Anaesth 2014; 112: 485-90.

18. Singh PM, Borle A, Gouda D, Makkar JK, Arora MK, Trikha A, et al. Efficacy of palonosetron in postoperative nausea and vomiting (PONV)-a meta-analysis. J Clin Anesth 2016; 34: 459-82.

19. Chattopadhyay S, Goswami S. Palonosetron versus ramosetron prophylaxis for control of postoperative nausea and vomiting after cesarean 
delivery under spinal anesthesia. J Obstet Gynaecol India 2015; 65: 28-33.

20. Hahm TS, Ko JS, Choi SJ, Gwak MS. Comparison of the prophylactic anti-emetic efficacy of ramosetron and ondansetron in patients at high-risk for postoperative nausea and vomiting after total knee replacement. Anaesthesia 2010; 65: 500-4.

21. Faerber L, Drechsler S, Ladenburger S, Gschaidmeier H, Fischer W. The neuronal 5- $\mathrm{HT}_{3}$ receptor network after 20 years of research-evolving concepts in management of pain and inflammation. Eur J Pharmacol 2007; 560: 1-8.

22. Lee KH, Rim SK, Lee JY, Lee SY, Lee SN, Lee EJ, et al. Effects of pretreatment with intravenous palonosetron for propofol-remifentanilbased anesthesia in breast and thyroid cancer surgery: a double-blind, randomized, controlled study. Korean J Anesthesiol 2014; 67: 13-9.

23. Backes JR, Bentley JC, Politi JR, Chambers BT. Dexamethasone reduces length of hospitalization and improves postoperative pain and nausea after total joint arthroplasty: a prospective, randomized controlled trial. J Arthroplasty 2013; 28(8 Suppl): 11-7.

24. Splinter WM, MacNeill HB, Menard EA, Rhine EJ, Roberts DJ, Gould MH. Midazolam reduces vomiting after tonsillectomy in children. Can J Anaesth 1995; 42: 201-3.

25. Liang X, Zhou M, Feng JJ, Wu L, Fang SP, Ge XY, et al. Efficacy of dexmedetomidine on postoperative nausea and vomiting: a meta-analysis of randomized controlled trials. Int J Clin Exp Med 2015; 8: 8450-71. 